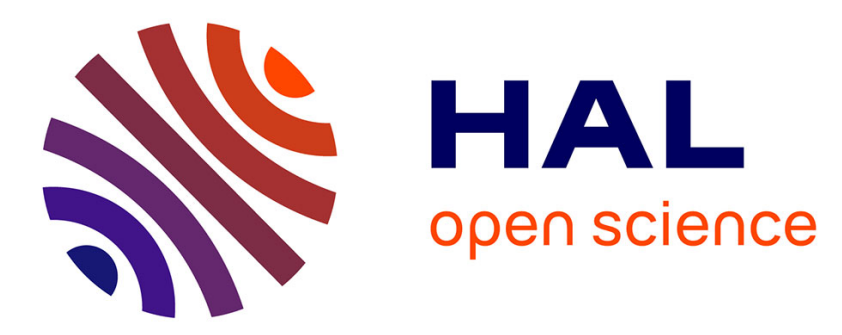

\title{
Volmer-Weber InAs quantum dot formation on InP (113)B substrates under the surfactant effect of Sb
}

Yu Zhao, Samuel J. C. Mauger, Nicolas Bertru, Hervé Folliot, Tony Rohel, Paul M. Koenraad

\section{- To cite this version:}

Yu Zhao, Samuel J. C. Mauger, Nicolas Bertru, Hervé Folliot, Tony Rohel, et al.. Volmer-Weber InAs quantum dot formation on InP (113)B substrates under the surfactant effect of Sb. Applied Physics Letters, 2014, 105 (3), pp.033113. 10.1063/1.4891505 . hal-01159201

\section{HAL Id: hal-01159201 https://hal.science/hal-01159201}

Submitted on 2 Jun 2015

HAL is a multi-disciplinary open access archive for the deposit and dissemination of scientific research documents, whether they are published or not. The documents may come from teaching and research institutions in France or abroad, or from public or private research centers.
L'archive ouverte pluridisciplinaire HAL, est destinée au dépôt et à la diffusion de documents scientifiques de niveau recherche, publiés ou non, émanant des établissements d'enseignement et de recherche français ou étrangers, des laboratoires publics ou privés. 


\section{AIP Aponed phosics \\ Letters}

\section{Volmer-Weber InAs quantum dot formation on InP (113)B substrates under the surfactant effect of $\mathrm{Sb}$}

Yu Zhao, Samuel J. C. Mauger, Nicolas Bertru, Hervé Folliot, Tony Rohel, and Paul M. Koenraad

Citation: Applied Physics Letters 105, 033113 (2014); doi: 10.1063/1.4891505

View online: http://dx.doi.org/10.1063/1.4891505

View Table of Contents: http://scitation.aip.org/content/aip/journal/apl/105/3?ver=pdfcov

Published by the AIP Publishing

\section{Articles you may be interested in}

Growth and characterization of InAs quantum dots on InP nanowires with zinc blende structure

J. Vac. Sci. Technol. B 31, 051803 (2013); 10.1116/1.4818509

Gallium diffusion into self-assembled InAs quantum dots grown on indium phosphide substrates Appl. Phys. Lett. 85, 3578 (2004); 10.1063/1.1806277

Wavelength control of $1.3-1.6 \mu \mathrm{m}$ light emission from the quantum dots self-formed in GaAs/InAs short-period superlattices grown on $\operatorname{lnP}(411)$ A substrates

J. Appl. Phys. 96, 1373 (2004); 10.1063/1.1765860

Formation of low-index facets in $\mathrm{Ga} 0.2$ In 0.8 As and $\ln A$ s islands on a $\operatorname{lnP}(113) \mathrm{B}$ substrate Appl. Phys. Lett. 74, 1680 (1999); 10.1063/1.123653

Ordered InAs quantum dots in InAIAs matrix on (001) InP substrates grown by molecular beam epitaxy Appl. Phys. Lett. 72, 2123 (1998); 10.1063/1.121296

Frustrated by

old technology?

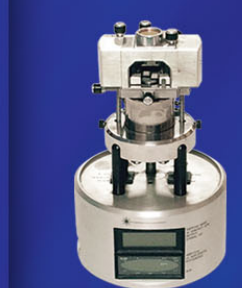

Is your AFM dead

and can't be repaired?

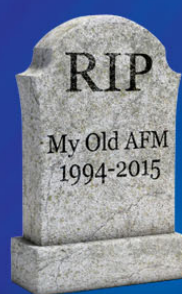

Sick of bad customer support?

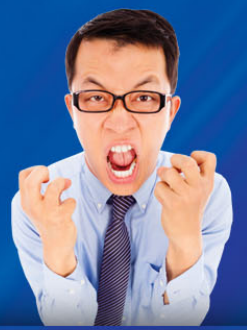

It is time to upgrade your AFM Minimum $\$ 20,000$ trade-in discount for purchases before August 31st

Asylum Research is today's technology leader in AFM 


\title{
Volmer-Weber InAs quantum dot formation on InP (113)B substrates under the surfactant effect of $\mathrm{Sb}$
}

\author{
Yu Zhao, ${ }^{1, a)}$ Samuel J. C. Mauger, ${ }^{2}$ Nicolas Bertru, ${ }^{1}$ Hervé Folliot, ${ }^{1}$ Tony Rohel, ${ }^{1}$ \\ and Paul M. Koenraad ${ }^{2}$ \\ ${ }^{1}$ Université Européenne de Bretagne, INSA, FOTON, UMR-CNRS 6082, 20 Avenue des Buttes de Coësmes, \\ F-35708 Rennes Cedex 7, France \\ ${ }^{2}$ COBRA Inter-University Research Institute, Eindhoven University of Technology, P.O. Box 513, \\ NL-5600MB Eindhoven, The Netherlands
}

(Received 11 April 2014; accepted 16 July 2014; published online 24 July 2014)

\begin{abstract}
We report on $\mathrm{Sb}$ surfactant growth of InAs nanostructures on $\mathrm{GaAs}_{0.51} \mathrm{Sb}_{0.49}$ layers deposited on InP (001) and on (113)B oriented substrates. On the (001) orientation, the presence of $\mathrm{Sb}$ significantly favors the two-dimensional growth regime. Even after the deposition of 5 mono-layers of InAs, the epitaxial film remains flat and InAs/ $\mathrm{GaAs}_{0.51} \mathrm{Sb}_{0.49}$ type-II quantum wells are achieved. On (113)B substrates, same growth runs resulted in formation of high density InAs islands. Microscopic studies show that wetting layer is missing on (113)B substrates, and thus, a VolmerWeber growth mode is concluded. These different behaviors are attributed to the surface energy changes induced by Sb atoms on surface. (C) 2014 AIP Publishing LLC.

[http://dx.doi.org/10.1063/1.4891505]
\end{abstract}

The hetero-epitaxy of strained semiconductor layers has been the subject of extensive research for the last couple of decades. Due to the lattice misfit between the epitaxial thin film and the substrate, the deposited materials often selforganize into nanometric three-dimensional (3D) islands in order to relax the strain energy. These islands are better known as quantum dots, and they are appreciated for their unique properties and applications in optoelectronic devices. Typical strained material systems producing quantum dots are $\mathrm{Ge} / \mathrm{Si}^{1}{ }^{1}$ (Ga)InAs/GaAs (001), ${ }^{2}$ and $\mathrm{InAs} / \mathrm{InP}(001) .^{3}$ In these systems, the epitaxial islands are formed under the so-called Stranski-Krastanow (S-K) growth mode. ${ }^{4}$ The deposited material remains flat and organizes into islands only after a critical thickness is reached. The coexistence of islands and a two-dimensional (2D) underlying wetting layer is an important characteristic of the $\mathrm{S}-\mathrm{K}$ growth mode. ${ }^{4-8}$ The formation of islands is energetically favored by the strain relaxation; it however creates extra free surface area that increases the total system energy. ${ }^{9}$ The coexistence of islands and wetting layer is, thus, considered to result from the balance of the strain energy and surface (interface) energies present in the epitaxial growth system. ${ }^{10}$ Nevertheless, the formation of $3 \mathrm{D}$ islands can be suppressed by deliberate introduction of certain surfactants, ${ }^{1,11,12}$ among which $\mathrm{Sb}$ is commonly used. Supplied during the epitaxial growth, the $\mathrm{Sb}$ atoms tend to segregate and they virtually 'float' on the growth front. ${ }^{11,13,14}$ Although barely incorporated into subsequent epitaxial layers, they can significantly modify the underlying growth processes and extend 2D growth regime. ${ }^{15,16}$

Surfactant effects are widely reported for epitaxial growth on standard (001) substrate, but its influence on the InAs deposition on high-index substrate is rarely reported. ${ }^{17}$ In this paper, we investigate and compare $\mathrm{Sb}$ effects during InAs deposition on (113)B and on (001)-oriented InP

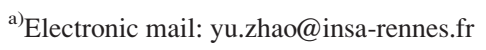

substrates. Samples were grown by solid source molecular beam epitaxy on $n$-type InP (001) and on (113)B substrates. The substrate temperature was fixed at $450^{\circ} \mathrm{C}$. Diatomic $\mathrm{As}_{2}$ and $\mathrm{Sb}_{2}$ fluxes were used, and the beam equivalent pressure ratio between group $\mathrm{V}$ and III elements was kept near unity during the growth of $\mathrm{GaAs}_{0.51} \mathrm{Sb}_{0.49}$ alloy to ensure good composition control. The lattice-matching condition of $\mathrm{GaAs}_{0.51} \mathrm{Sb}_{0.49}$ was checked by $\mathrm{X}$-ray diffraction on test samples. After the growth of $40 \mathrm{~nm}$-thick $\mathrm{GaAs}_{0.51} \mathrm{Sb}_{0.49}$ layers, the InAs was deposited at $0.3 \AA / \mathrm{s}$ on a (001) and a (113)B substrates during the same growth run. Although the growth rate was measured by X-Ray diffraction on (001) substrates, it is considered the same on (113)B substrates since the sticking coefficient of indium is equal to unity under the given conditions. ${ }^{18}$ After the InAs deposition, a $30 \mathrm{~s}$ growth interrupt under $\mathrm{As}_{2}$ was performed. Three sets of samples were elaborated for atomic force microscopy (AFM), photoluminescence (PL), and cross-sectional scanning tunneling microscopy (X-STM), respectively. The AFM samples were cooled down after the InAs deposition. The AFM measurements were performed in contact mode. On samples dedicated to PL measurement, a $40 \mathrm{~nm}$ $\mathrm{GaAs}_{0.51} \mathrm{Sb}_{0.49}$ capping layer was deposited. Two additional $\mathrm{GaAs}_{0.56} \mathrm{Sb}_{0.44}$ layers were added to suppress type-II transitions occurring at $\mathrm{GaAsSb} / \mathrm{InP}$ interfaces. ${ }^{19} \mathrm{PL}$ signal was excited by a $532 \mathrm{~nm}$ laser. Finally, for the X-STM sample, four planes of InAs from 3 mono-layers (ML) to $6 \mathrm{ML}$ were grown and separated by $40 \mathrm{~nm}$-thick $\mathrm{GaAs}_{0.51} \mathrm{Sb}_{0.49}$ layers. The X-STM measurements were performed on (110) cleavage planes.

Figure 1 shows AFM images and associated height profiles recorded on $4 \mathrm{ML}$ samples. For deposit performed on (001) sample, small height fluctuations are observed. A root mean square roughness of $0.2 \mathrm{~nm}$ is measured, which is comparable to those observed on initial GaAsSb surface. Without Sb supply on surface, a critical thickness for island nucleation about $2 \mathrm{ML}$ has been reported. ${ }^{20-22}$ The absence 

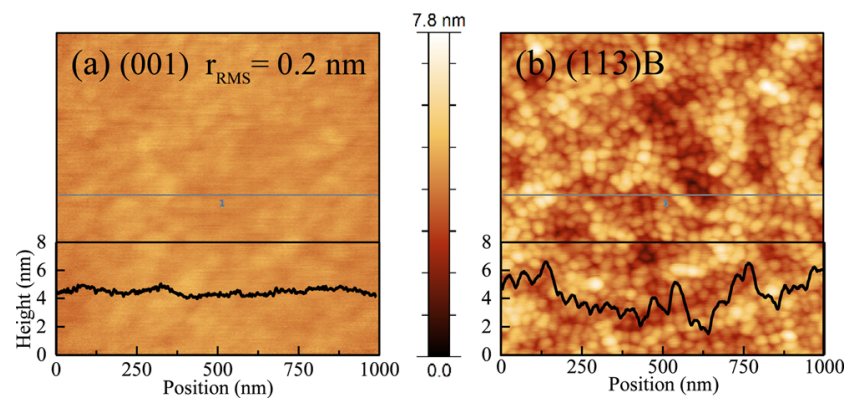

FIG. 1. AFM images and profiles of 4 ML InAs deposited on GaAsSb matrices prepared (a) on an InP (001) substrate and (b) on an InP (113)B substrate. Line profiles are extract through the middle of the scanned areas.

of InAs islands on GaAsSb (001) surface, thus, reflects the commonly observed surfactant effect of $\mathrm{Sb}$, which helps to maintain a 2D growth mode of strained epitaxial layer. ${ }^{15,16}$

For deposits performed during the same growth run on (113)B substrate (Figure 1(b)), a large number of islands are observed and its height profile reveals a large height undulation. The sizes of the InAs islands are quite uniform, and no dislocated island ${ }^{23}$ is detected. Figure 2 shows island densities and average heights versus amount of InAs deposited extracted from AFM images. The island densities increase monotonously with the amount of deposited InAs. A high island density of about $1 \times 10^{11} \mathrm{~cm}^{-2}$ was achieved after a deposition of $5 \mathrm{ML}$ InAs. At the same time, the islands average height is constantly rising as the InAs deposition increases. $^{22}$ The enhanced island density obtained under $\mathrm{Sb}$ demonstrates that its usual surfactant effect is not working for deposit performed on (113)B orientation.

Figure 3(a) shows PL spectra from (001) samples recorded under room temperature and low excitation power (about $20 \mathrm{~W} / \mathrm{cm}^{2}$ ). Two PL peaks are observed. The highenergy peaks appear independent of the amount of InAs deposited, and their energies are close to band gap of $\mathrm{GaAs}_{0.51} \mathrm{Sb}_{0.49}(0.75 \mathrm{eV}) .{ }^{24} \mathrm{We}$ attributed them to recombination within GaAsSb. The low energy PL peaks red-shift with the amount of InAs. Moreover, they show a one-third power dependence with excitation power (inset of Figure $3(\mathrm{a})$ ), which is the signature of a type-II band lineup. We assign low energy peaks to recombination between electrons confined within InAs layer and holes within GaAsSb barriers. Transition energies calculated for strained InAs

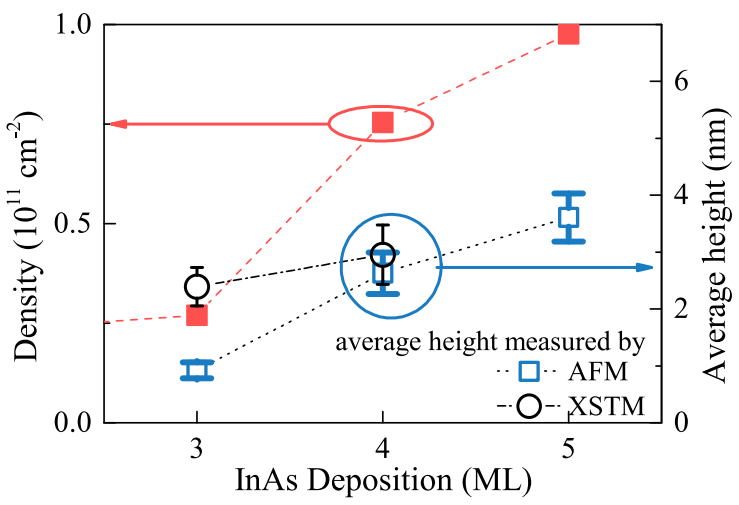

FIG. 2. Island densities and average heights extracted from AFM observation of unburied InAs islands obtained on (113)B substrates. X-STM measured average heights are also provided for information.

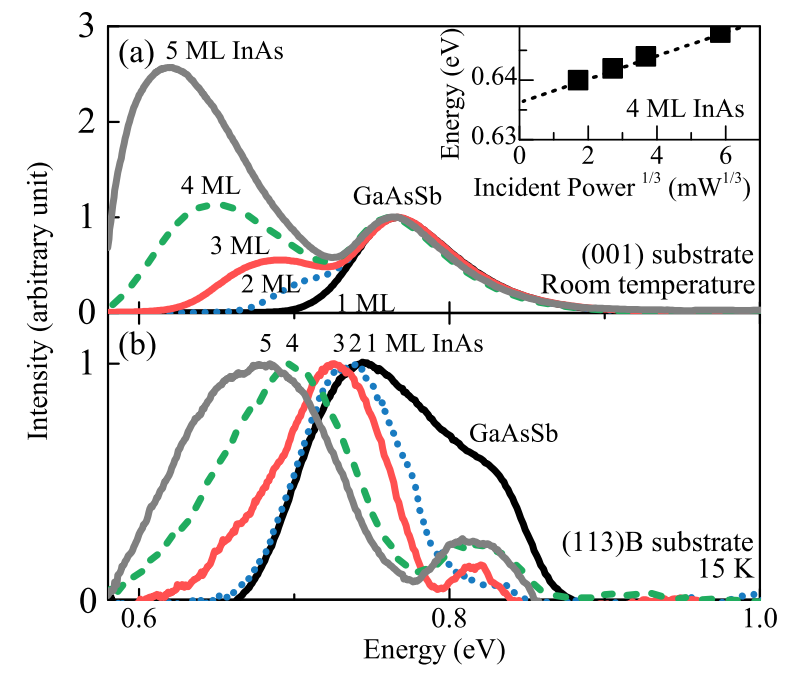

FIG. 3. PL spectra of InAs/GaAsSb nanostructures obtained (a) on InP (001) substrates and (b) on InP (113)B substrates. These spectra were obtained under a relatively low excitation power density of about $20 \mathrm{~W} / \mathrm{cm}^{2}$. In (a), GaAsSb-related peak intensities are normalized to unity, while in (b), InAsrelated peak intensities are set to one. The inset of (a) shows the evolution of the peak energy of the 4 ML sample under different excitation powers.

quantum wells using a 6-band $k \cdot p$ code (not shown) agree well with experimental values. Such agreement shows that InAs layers are flat and thick InAs quantum wells can be achieved on (001) substrates using Sb surfactant effect.

PL spectra recorded from (113)B samples at $15 \mathrm{~K}$ are reported in Figure 3(b). As previously, we assign the highenergy peaks to recombination within GaAsSb. The second peaks are broad and are more separated from GaAsSb peak than those observed from (001) samples. Such results can be attributed to the formation of quantum dots on (113)B substrates and confirm the results obtained by AFM. It is worth noting that InAs PL peak observed from the $1 \mathrm{ML}$ sample is broad and its energy is lower than that calculated for a onemonolayer quantum well. Moreover, wetting layer related PL signals are not detected for any of these samples. These results suggest a very low critical thickness and the possibility of missing wetting layer.

The structural characterization of InAs deposit on (113)B in presence of $\mathrm{Sb}$ was performed by X-STM. Figure 4 reports two large-scale X-STM images from planes in which $3 \mathrm{ML}$ and $4 \mathrm{ML}$ InAs have been deposited. High-quality cleaved

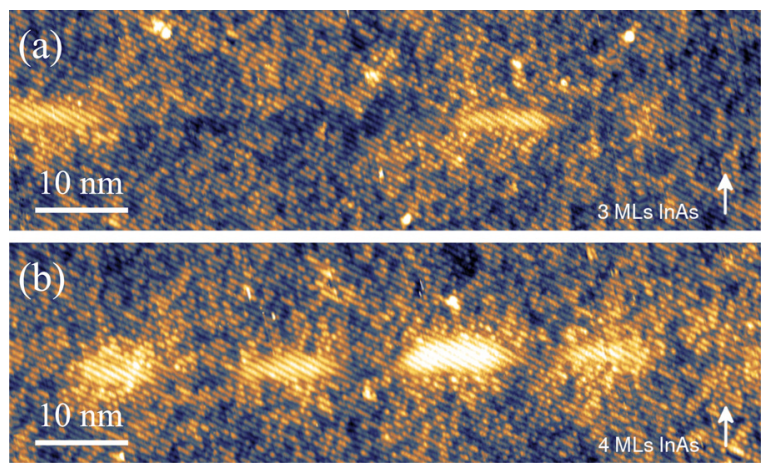

FIG. 4. X-STM images of InAs islands formed by (a) $3 \mathrm{ML}$ and (b) $4 \mathrm{ML}$ InAs deposition on GaAsSb (113)B buffer layers. These images were recorded under constant-current mode with a sample bias of $-3.2 \mathrm{~V}$. The presented areas are $81 \times 24 \mathrm{~nm}^{2}$. 
surfaces were not obtained from zones containing $5 \mathrm{ML}$ and 6 ML layers, probably due to their high levels of strain. The images were taken under constant-current mode with a large negative sample bias of $-3.2 \mathrm{~V}$. The contrast is related to electronic position of the tunneling states so that materials of larger band gap appear with darker contrasts. The bright zones in the images correspond to InAs islands, while their surroundings with randomly distributed bright dots reflect GaAsSb layers. In Figure 4(a), the two InAs islands formed by $3 \mathrm{ML}$ of InAs deposition have flat lens shape, and their centers are separated by a relative long distance of about $50 \mathrm{~nm}$. Such inter-island spacing is equivalent to an areal density of $4 \times 10^{10} \mathrm{~cm}^{-2}$, which is in the same order of magnitude as that observed by AFM. For 4 ML deposit, island heights increase while the inter-island space decreases almost by a factor of two. Such observations are consistent with the monotonously growing island height and sharply increasing island density observed by AFM on unburied islands (Figure 2). The islands formed after 4 ML InAs deposition show clear facets. Such facets are composed of $\{001\},\{110\}$, and $\{111\}$ crystallographic planes. For both images, the image contrast is homogeneous inside the islands while only a few bright spots representing $\mathrm{Sb}$ atoms are present in their peripheries. Such observations show that InAs islands are composed of almost pure InAs and that $\mathrm{Sb}$ intermixing does not occur during growth. Moreover, wetting layers between islands are not observed by X-STM. In a previous paper, ${ }^{8}$ we studied InAs islands grown on (113) B substrates for which the $\mathrm{Sb}$ is supplied on surface after island formation. In that case, wetting layers are obviously observed on X-STM images recorded in similar conditions. Furthermore, at the interface between GaAsSb matrix and GaAsSb capping layer, a dark line is observed which corresponds to a high band gap material and a low band gap InAs layer can be excluded. Arsenic rich $\mathrm{GaAsSb}$ alloy, formed during the growth interruption under $\mathrm{As}_{2}$ after InAs formation by $\mathrm{Sb}$ depletion, is probably at the origin of the dark line. Therefore, $\mathrm{Sb}$ on surface during the deposition of InAs had opposite effects on (001) and on (113) B substrates. On (001) substrates, an increase of the 2D growth is observed as usual for a surfactant. In contrast, on (113)B substrates, islands of high density are formed, and the wetting layer is missing, which is the signature of a VolmerWeber growth mode.

The surfactant effect of $\mathrm{Sb}$ is frequently interpreted as reduced mass transport under $\mathrm{Sb}$ surface coverage. ${ }^{15,25,26}$ Under such framework, the use of Sb reduces the indium surface diffusion length and blocks indium migration to island nucleation site. Such an argument agrees with what we have observed earlier on (001) substrate, where the formation of InAs islands is prevented. However, it cannot explain why islands of high density are formed on (113)B substrate in spite of the presence of $\mathrm{Sb}$.

Surfactant effect has been also related to the change of surface energy, induced by surfactant adsorption on surface. ${ }^{26}$ If we here simply assume that $\mathrm{Sb}$ reduces surface energies independently of crystallographic orientations, the experimental observations above cannot be explained. Actually, by reducing the surface energy, surfactant adsorption would reduce the energy cost associated with creating extra facets and so favors the island formation. ${ }^{9}$ However, (a)

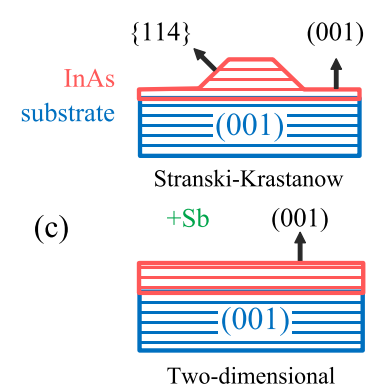

(b)

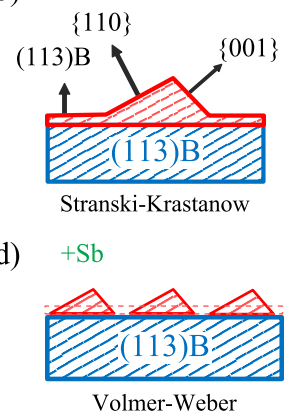

FIG. 5. Possible results of InAs deposition on different substrates, with or without the influence of Sb. (a) and (b) represent Stranski-Krastanow InAs islands formed without the influence of $\mathrm{Sb}$ on either type of substrate. (c) illustrates 2D InAs layer obtained under Sb-mediated growth on a (001) substrate. (d) represents the high-density InAs islands formed without wetting layer on a (113)B substrate.

InAs islands made on (001) and on (113)B substrates demonstrate facets of different crystallographic orientations. InAs islands formed on InP (001) substrates show highindex facets like (114), ${ }^{27,28}$ while the islands obtained on (113)B substrates are found to have low-index facets in $\{001\}\{110\}$ and $\{111\}$ families. ${ }^{29,30}$ If we assume that the adsorption of $\mathrm{Sb}$ noticeably reduces the surface energy of low-index facets like (001), (110), or (111) while it reduces the high-index ones like $\{113\}$ or $\{114\}$ to a smaller extent or even increases their energies, the drastically different effects of $\mathrm{Sb}$ versus substrate orientations observed can then be explained (Figure 5). On (001) substrate, the use of $\mathrm{Sb}$ would stabilize the low-index (001)-oriented wetting layer while it does not encourage the formation of highindex facets of InAs islands. Therefore, the presence of $\mathrm{Sb}$ annihilates the formation of InAs islands and extends 2D growth regime on InP (001) substrates. On InP (113)B substrates, because InAs islands show low-index facets, adsorption of $\mathrm{Sb}$ on facets reduces the energy cost associated with island formation and hence favors island nucleation. Moreover, the reduced energy of islands can shift the balance between the wetting layer and the islands, so that it may destabilize the high-index InAs wetting layer. Therefore, the surface orientation dependent surface energy modification induced by $\mathrm{Sb}$ allows a simple explanation to the experimental observations presented in this paper. It is worth noting that anisotropic changes of surface energy induced by $\mathrm{Sb}$ have been observed in other material systems. ${ }^{31,32}$ However, further investigation is required to measure surface energy change with surfactant.

In this paper, the growth of InAs on Sb-rich surface of GaAsSb layers deposited on InP (001) and on (113)B substrates is studied. On InP (001) substrates, the presence of $\mathrm{Sb}$ annihilates the formation of high-density InAs islands and InAs/GaAsSb type-II quantum wells are achieved. In contrast, on (113)B substrate, formation of InAs/GaAsSb islands under Volmer-Weber mode is observed. We show that such substrate orientation dependent behaviors can be interpreted by surface orientation dependent surface energy modification induced by the presence of $\mathrm{Sb}$.

This work was supported by the French National Research Agency through the project NAIADE (ANR-11-BS10-017). 
One of the authors, Yu Zhao, would like to thank China Scholarship Council for financial support.

${ }^{1}$ M. Copel, M. C. Reuter, E. Kaxiras, and R. M. Tromp, Phys. Rev. Lett. 63, 632 (1989).

${ }^{2}$ O. G. Schmidt, T. Kirstaedter, N. N. Ledentsov, D. Bimberg, V. M. Ustinov, A. Y. Egorov, A. E. Zhukov, M. V. Maximov, P. S. Kop'ev, and Z. I. Alferov, in Eighth International Conference on Indium Phosphide and Related Materials (IEEE, 1996) pp. 727-730.

${ }^{3}$ F. Lelarge, B. Dagens, J. Renaudier, R. Brenot, A. Accard, F. V. Dijk, D. Make, O. L. Gouezigou, J.-G. Provost, F. Poingt, J. Landreau, O. Drisse, E. Derouin, B. Rousseau, F. Pommereau, and G.-H. Duan, IEEE J. Sel. Top. Quantum Electron. 13, 111 (2007).

${ }^{4}$ D. Bimberg, M. Grundmann, and N. N. Ledentsov, Quantum Dot Heterostructures (Wiley, 1999).

${ }^{5}$ G. Abstreiter, P. Schittenhelm, C. Engel, E. Silveira, A. Zrenner, D. Meertens, and W. Jäger, Semicond. Sci. Technol. 11, 1521 (1996).

${ }^{6}$ P. Offermans, P. M. Koenraad, R. Nötzel, J. H. Wolter, and K. Pierz, Appl. Phys. Lett. 87, 111903 (2005).

${ }^{7}$ C. Celebi, J. M. Ulloa, P. M. Koenraad, A. Simon, A. Letoublon, and N. Bertru, Appl. Phys. Lett. 89, 023119 (2006).

${ }^{8}$ W. Lu, M. Bozkurt, J. G. Keizer, T. Rohel, H. Folliot, N. Bertru, and P. M. Koenraad, Nanotechnology 22, 055703 (2011).

${ }^{9}$ C. W. Snyder and B. G. Orr, Phys. Rev. Lett. 70, 1030 (1993).

${ }^{10}$ L. G. Wang, P. Kratzer, M. Scheffler, and N. Moll, Phys. Rev. Lett. 82, 4042 (1999).

${ }^{11}$ T. F. Kuech, AIP Conf. Proc. 916, 288 (2007).

${ }^{12}$ E. Tournié, N. Grandjean, A. Trampert, J. Massies, and K. Ploog, J. Cryst. Growth 150(1), 460 (1995).

${ }^{13}$ R. Kaspi and K. R. Evans, J. Cryst. Growth 175-176(2), 838 (1997).

${ }^{14}$ X. Wallart, S. Godey, Y. Douvry, and L. Desplanque, Appl. Phys. Lett. 93, 123119 (2008).
${ }^{15}$ J. C. Harmand, L. H. Li, G. Patriarche, and L. Travers, Appl. Phys. Lett. 84, 3981 (2004).

${ }^{16}$ C. Gatel, H. Tang, C. Crestou, A. Ponchet, N. Bertru, F. Doré, and H. Folliot, Acta Mater. 58, 3238 (2010).

${ }^{17}$ G. A. M. Sáfar, W. N. Rodrigues, L. A. Cury, H. Chacham, M. V. B. Moreira, S. L. S. Freire, and A. G. D. Oliveira, Appl. Phys. Lett. 71, 521 (1997).

${ }^{18}$ C. Heyn, Phys. Rev. B 66, 075307 (2002).

${ }^{19}$ O. Ostinelli, G. Almuneau, and W. Bächtold, Semicond. Sci. Technol. 21, 681 (2006).

${ }^{20}$ M. Gendry, V. Drouot, C. Santinelli, and G. Hollinger, Appl. Phys. Lett. 60, 2249 (1992)

${ }^{21} \mathrm{H}$. Li, J. Wu, B. Xu, J. Liang, and Z. Wang, Appl. Phys. Lett. 72, 2123 (1998).

${ }^{22}$ S. Fréchengues, N. Bertru, V. Drouot, C. Paranthoen, O. Dehaese, S. Loualiche, A. Le Corre, and B. Lambert, J. Cryst. Growth 209, 661 (2000).

${ }^{23}$ S. Fréchengues, N. Bertru, V. Drouot, B. Lambert, S. Robinet, S. Loualiche, D. Lacombe, and A. Ponchet, Appl. Phys. Lett. 74, 3356 (1999).

${ }^{24}$ I. Vurgaftman, J. R. Meyer, and L. R. Ram-Mohan, J. Appl. Phys. 89, 5815 (2001)

${ }^{25}$ J. Massies and N. Grandjean, Phys. Rev. B 48, 8502 (1993).

${ }^{26}$ D. Kandel and E. Kaxiras, Solid State Phys. 54, 219 (1999).

${ }^{27}$ A. Ponchet, A. L. Corre, H. L'Haridon, B. Lambert, and S. Salaün, Appl. Phys. Lett. 67, 1850 (1995).

${ }^{28}$ A. Ponchet, A. Le Corre, A. Godefroy, S. Salaün, and A. Poudoulec, Microelectron. J. 26, 783 (1995).

${ }^{29}$ Y. Temko, T. Suzuki, and K. Jacobi, Appl. Phys. Lett. 82, 2142 (2003).

${ }^{30}$ C. Cornet, P. Turban, N. Bertru, S. Tricot, O. Dehaese, and A. Le Corre, in EuroMBE (Alpe d'Huez, France, 2011).

${ }^{31}$ L. Zhang, H. F. Tang, J. Schieke, M. Mavrikakis, and T. F. Kuech, J. Appl. Phys. 92, 2304 (2002).

${ }^{32}$ D. J. Eaglesham, F. C. Unterwald, and D. C. Jacobson, Phys. Rev. Lett. 70, 966 (1993). 